$10-8-2021$

\title{
Harnessing data to end child marriage: Summarizing learnings to- date
}

Stephanie Psaki

Momoe Makino

Christina Misunas

Population Council

Erica Soler-Hampejsek

Fatima Zahra

Population Council

Follow this and additional works at: https://knowledgecommons.popcouncil.org/departments_sbsr-pgy

Part of the Family, Life Course, and Society Commons How does access to this work benefit you? Let us know!

\section{Recommended Citation}

Psaki, Stephanie, Momoe Makino, Christina Misunas, Erica Soler-Hampejsek, Fatima Zahra, and et al. 2021. "Harnessing data to end child marriage: Summarizing learnings to-date," GIRL Center Research Brief No. 8. New York: Population Council. 


\title{
GIRL然Center
}

FOR INNOVATION, RESEARCH, AND LEARNING

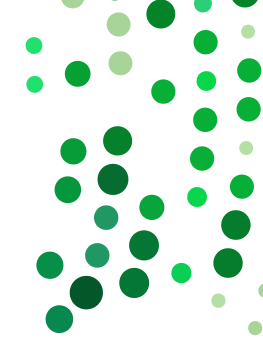

\section{GIRL Center Research Brief}

No. 8 October 2021

\section{HARNESSING DATA TO END CHILD MARRIAGE: SUMMARIZING LEARNINGS TO-DATE}

\section{STEPHANIE PSAKI, MOMOE MAKINO, CHRISTINA MISUNAS, ERICA SOLER, FATIMA ZAHRA ET AL. ${ }^{a}$}

\begin{abstract}
AT A GLANCE
In this brief we summarize the key findings from five papers published as part of a special issue examining child marriage and interventions to address it. While the findings from each of the papers are briefly noted, this brief focuses on the importance of context in understanding the drivers and impact on child marriage. Based key findings, the brief offers cross-cutting recommendations for research and programs.
\end{abstract}

\section{BACKGROUND}

The evidence base on child marriage has grown substantially in the past decade including numerous papers on key drivers and associations across many countries as well as three published systematic reviews on what interventions work to delay marriage..$^{1,2,3}$ The systematic reviews focus on a growing but geographically narrow body of evidence, as many countries have little, or no evidence included in these reviews while other countries and regions have a more robust body of evidence. Despite the growing body of global evidence, there remains a gap in understanding which drivers are most important across which contexts and which interventions work best to address those drivers. New research from the Population Council aims to draw on available data to understand the drivers of child marriage, the level at which they operate and influence, and how programs and policies should address these drivers to delay marriage.
New conceptual framework:

- Psaki et al. present a conceptual framework, developed using a literature review of the drivers of child marriage and a consultative process with key stakeholders. ${ }^{4}$ This framework aims to simplify a display of the main drivers of child marriage, the relationships between these drivers, and provide guidance for developing programs and policies

Drivers of child marriage:

- Misunas et al. examine factors associated with child marriage. ${ }^{5}$ They find that in Burkina Faso the importance of schooling and existence of alternative pathways for girls beyond marriage appears crucial to reducing child marriage.

(Continued on page 2.) 
(Continued from page 1.)

In Tanzania, early sexual initiation among girls was common and strongly associated with marriage during childhood; parents' fear of premarital sex and pregnancy emerged as a significant factor.

- Zahra et al. examine how the drivers of child marriage influence the health outcomes of adolescent girls and young women in India, Malawi, and Zambia. ${ }^{6}$ They find that pregnancy before marriage is associated with fewer antenatal visits and hospital-based births in Malawi than pregnancy after marriage; the latter association was not found in Zambia. Agency in marital partner choice is associated with change in depressive symptoms after marriage for some AGYW in India.

Interventions to address child marriage:

- Makino et al. examine the effectiveness of girl-centered asset-building interventions to address child marriage in Bangladesh and Zambia. ${ }^{7}$ They find that effectiveness of the same intervention may differ depending on the contexts, such as premarital sex and availability of work opportunities.

- Soler et al. investigate whether child marriage changes young people's ability to translate education into paid employment, drawing on longitudinal data from Malawi. ${ }^{8}$ They find that child marriage is not a strong moderator of the relationship between education and work, particularly among young married women, and that delaying marriage to age 18 is not a panacea as young people who marry as adults still face low education outcomes.

\section{KEY FINDINGS}

\section{Context Matters}

Context matters for understanding the drivers and impacts of child marriage. Understanding the specific context in which child marriage occurs helps us understand why the problem persists, and may also help inform appropriately targeted and effective programs and policies.

The drivers of child marriage-and their influence-vary across context

The papers together show that the main drivers of child marriage, as presented in the framework in Psaki et al., influence child marriage differently based on each context. ${ }^{b}$
- How the drivers of child marriage operate and interact, including across multiple levels and the relative degree of influence of each driver on child marriage. A few examples from the papers include:

- Poverty and gender inequitable social norms seem to contribute to a lack of opportunity for girls in many settings, which might make child marriage more appealing, both to girls and their families (Bangladesh, Niger, Malawi)

- Social norms, particularly around the avoidance of girls' sexuality, are closely tied with norms around marriage, pregnancy, and fear of pregnancy (Bangladesh, Malawi)

b These main drivers are:

- Social norms and attitudes towards child marriage and roles for women and girls broadly;

- Poverty and economic factors that encourage child marriage as a coping strategy for financial instability, insecurity or as a livelihood strategy for girls;

- $\quad$ Lack of agency among girls to decide when and whom to marry;

- Lack of opportunity for girls and women in education and livelihood alternatives to marriage; and

- Fear of girls' sexuality and pregnancy that drive child marriage as a means to preserve honor or protect against out of wedlock pregnancy that may be associated with shame. 
- There are levels of influence that vary: For example, in Burkina Faso a lack agency or engagement in very early sexual initiation is an important individual-level factor, but at the community level social norms, particularly views on child marriage among fathers in the community were associated with child marriage.

- The association between drivers of child marriage and other outcomes (e.g., health, education) is still unclear. Some findings include:

- Having agency in marital partner choice associated with a change in reported depressive symptoms in Uttar Pradesh, India.

- We find no evidence that pregnancy before marriage leads to worse child health outcomes than pregnancy after marriage in Malawi and Zambia.

While there are similarities across contexts, findings suggest that we need to be attuned to context-specific factors that may amplify or reduce the influence of certain drivers.

Even proven-effective interventions need to be better-tailored to the local context

Understanding which of these factors may be most important in diverse settings within and across countries is important for designing and implementing locally adapted solutions to end the practice. For example, in settings where premarital pregnancy is an important driver of child marriage, interventions to address pregnancy may be more important in that setting than in areas where premarital sex and pregnancy are rare.

The current evidence base builds on studies from a limited number of countries and biased towards a particular context, namely South Asia where marriages tend to involve family arrangements and premarital sex is rare. While there is an ongoing discussion on how the evidence base of 'what works' can and should translate to programs, findings from the new papers speak to understanding the context and tailoring child marriage interventions appropriately. ${ }^{9-10}$

- Social contexts and girls' backgrounds can affect the effectiveness of interventions aimed at delaying marriage.

- Child marriage can limit young women's ability to translate schooling to income-generating opportunities.

- Marriage after 18 does not necessarily confer better livelihood outcomes and interventions need to address work opportunities for girls and women.

\section{RECOMMENDATIONS}

While findings from each paper present their own recommendations for research, program, and policy implications, we offer a few crosscutting recommendations based on the key findings:

- Effective interventions should be tested for transferability to other contexts.

- Design of interventions should consider which drivers are most influential in that setting and at which level those drivers are known or hypothesized to operate (see GIRL Center Brief no. 7).

- Specific guidance is needed to help those designing programs know how to identify important child marriage drivers in their context and choose intervention strategies that are best suited to address those drivers.

- Additional research is needed to understand how the drivers of child marriage influence other health and education outcomes, and how this differs across contexts.

- The influence of Covid-19 is expected to increase child marriage in some contexts and stall global progress; research is needed to better understand how stress and insecurity influence child marriage and which program and policy efforts are best positioned to protect girls during times of stress and insecurity and mitigate the impact. ${ }^{11}$ 


\section{REFERENCES}

1. Lee-Rife, S., A. Malhotra, A. Warner, A. M. Glinski. 2012. What Works to Prevent Child Marriage: A Review of the Evidence. Studies in Family Planning, 43(4), 287-303. https://doi. org/10.1111/j.1728-4465.2012.00327.x.

2. Kalamar, A. M., S. Lee-Rife, \& M. J. Hindin. 2016. Interventions to Prevent Child Marriage Among Young People in Low- and Middle-Income Countries: A Systematic Review of the Published and Gray Literature. Journal of Adolescent Health, 59(3), S16-S21. https://doi.org/10.1016/J. JADOHEALTH.2016.06.015.

3. Malhotra, A., \& S. Elnakib. 2021. 20 Years of the Evidence Base on What Works to Prevent Child Marriage: A Systematic Review. Journal of Adolescent Health. https://doi.org/10.1016/j. jadohealth.2020.11.017.

4. Psaki, S., A.J. Melnikas, E. Haque, G. Saul, C. Misunas, S.K. Patel, T. Ngo, S. Amin. What are the drivers of child marriage? A conceptual framework to guide policies and programs. Journal of Adolescent Health. Forthcoming.

5. Misunas, C., A. Erulkar, L. Apicella, T. Ngo, S. Psaki. What influences girls' age at marriage in Burkina Faso and Tanzania? Exploring the contribution of individual, household, and community level factors. Journal of Adolescent Health. Forthcoming.

6. Zahra, F., K. Austrian, M. Gundi, S. Psaki, T. Ngo. Drivers of marriage and health outcomes among adolescents: Evidence from sub-Saharan Africa and South Asia. Journal of Adolescent Health. Forthcoming.

7. Makino, M., T. Ngo, S. Psaki, S. Amin, K. Austrian. Heterogenous impacts of interventions aiming to delay girls' marriage and pregnancy across girls' background and social contexts. Journal of Adolescent Health. Forthcoming.
8. Soler-Hampejsek, E., B. Kangwana, K. Austrian, S. Amin, S. Psaki. Education, child marriage, and work outcomes among young people in rural Malawi. Journal of Adolescent Health. Forthcoming.

9. Chandra-Mouli, V., M. Plesons. 2021. A groundbreaking systematic review, but that alone is not enough to change the course of programming on child marriage prevention. Journal of Adolescent Health. 68: 833-835.

10. Aguilera, S., D. Green, M. Greene, C. E. Izugbara, E. Murphy-Graham et al. Letter to the Editor of the Journal of Adolescent Health. https://www. jahonline.org/article/S1054-139X(21)00383-9/ fulltext.

11. UNFPA. 2020. "Millions more cases of violence, child marriage, female genital mutilation, unintended pregnancy expected due to the COVID-19 pandemic." https:// www.unfpa.org/news/millions-more-casesviolence-child-marriage-female-genitalmutilation-unintended-pregnancies. Accessed March 92021.

The Girl Innovation, Research, and Learning (GIRL) Center is a global research center that generates, synthesizes, and translates evidence to transform the lives of adolescent girls. Through rigorous research about what works - and what doesn't - we can better direct limited resources to support evidencebased solutions that improve girls' lives.

popcouncil.org/girlcenter

Recommended citation: Psaki, S., M. Makino, C. Misunas, E. Soler, F. Zahra et al. 2021. "Harnessing Data to End Child Marriage: Summarizing Learnings To-Date." GIRL Center Research Brief No. 8. New York: Population Council. 